\title{
¿'Desarrollo integral' o 'prejuicio humanista'?: Una problematización de supuestos en la doctrina social de la Iglesia
}

\section{INTRODUCCIÓN}

Desde la doctrina social de la Iglesia (DSI) no parece difícil vincular el lema bíblico: "Para que tengan vida en abundancia" (Jn 10, 10), con la categoría de 'desarrollo integral' introducida por Juan XXIII en Mater et Magistra, desarrollada por Pablo VI (Populorum Progressio) y Juan Pablo II (Sollicitudo rei Sociali). Lo que sí ha perdido su prístina evidencia es que el 'desarrollo integral' pueda ser resultante del modelamiento intencional de la sociedad.

Pensando en la actualidad de la DSI de cara a los actuales desafíos que se plantean en la sociedad contemporánea, nos interesa llamar la atención sobre un supuesto fundamental que está a la base del concepto de desarrollo, tal como ha sido trabajado conceptualmente desde Juan XXIII en adelante. Como se mostrará luego, en la DSI la categoría de 'desarrollo integral' no solo tiene una explícita connotación normativa, sino que además refleja una teoría social implícita tal que supone una línea de continuidad entre individuo y sociedad. Y nuestro problema se plantea cuando esta continuidad es contestada desde una de las más influyentes teorías sociales contemporáneas. Nos referimos a la teoría de los sistemas sociales de Niklas Luhmann que, hasta donde alcanzamos a entender, se constituye en una verdadera interpelación, cuando no impugnación, a los deseos bienintencionados de toda teoría normativa sobre el desarrollo (entre ellas, la DSI). De ahí que, más que intentar una exégesis del concepto en las formulaciones magisteriales, nos interesemos por su actualidad en el contexto de las transformaciones sociales contemporáneas.

Para relevar la importancia de la cuestión que nos ocupa, tomo ocasión para recordarles la crítica -que tal vez pasó inadvertida-que P. Morandé hiciera a la DSI en la jornada de enero de la Facultad de Teología. Refiriéndose a las insuficiencias de la teología, sostuvo allí:

Como científico social, sin embargo, me llaman la atención sus insuficiencias [de la teología] en la llamada Doctrina Social de la Iglesia, en la que todavía se presenta una visión jerarquizada de la sociedad a partir de lo que Kant 
llamaba la "voluntad legislativa" de la razón humana, aunque subordinada a la ley moral natural, que pone en el centro, por consecuencia, el orden político de un Estado respetuoso de los derechos humanos fundamentales, pero que no logra mantener coherentemente el mismo enfoque cuando se desplaza al ámbito de la familia y de las sociedades intermedias, o al ámbito de la economía de empresas y del mercado. Por decir así, se privilegia el punto de referencia institucional de la vida social, sin que quede claro, en cambio, el rol que juega la experiencia cotidiana de las personas, el conocimiento científico, la tecnología ni, en general, la producción y gestión de la información en la vida social.

La crítica de P. Morandé está sustentada en su apropiación (1) del aparato teórico de la teoría de sistemas de Luhmann. Como indicaremos luego, esta teoría social postula la imposibilidad en una sociedad compleja, funcionalmente diferenciada, de contar con un centro rector desde donde configurar la sociedad mundial. Tal teoría, y P. Morandé con ella, busca distanciarse de 'una visión jerarquizada de la sociedad' que ya ha perdido los fundamentos sociales que la sustentaron por siglos. Por eso, la crítica se dirige exactamente a un supuesto fundamental de toda la DSI que ella absorbió de la vieja tradición europea: la posibilidad de modelar políticamente la sociedad. Este supuesto nos parece especialmente reconocible en la tematización que la DSI ha hecho desde Mater et Magistra de la categoría de 'desarrollo integral'.

Esta exploración demandará precisar: (I) el carácter normativo del concepto de desarrollo en la DSI y su supuesto de modelamiento de la sociedad; (II) la crítica luhmanniana al 'prejuicio humanista' (supuesto de continuidad entre individuo y sociedad), y (III) algunos alcances que esta discusión acarrea para los desarrollos futuros de la DSI.

El 'desarrollo integral' es una categoría normativa extrabíblica que emerge en condiciones de modernidad. Surge -dirá Juan Pablo II- como "la expresión moderna de una dimensión esencial de la vocación del hombre" (SRS 30). Como tantos otros conceptos saturados normativamente (justicia social, democracia, derechos humanos, bien común, solidaridad, subsidiaridad, etc.), la incorporación de esta categoría refleja el carácter de sistema abierto de la DSI. Ella se ha formado (y se forma) al contacto con nuevos problemas y/o con nuevas formas de plantearlos. Que "La doctrina social de la Iglesia no ha sido pensada desde el principio como un sistema orgánico, sino que se ha formado en el curso del tiempo, (...)" (Compendio Doctrina Social de la Iglesia $N^{0} 72$ ), habla de la historicidad de un pensamiento que surge del

(1) A. Mascareño clasifica a P. Morandé entre aquellos seguidores de Luhmann que permutan la teoría de sistemas con otros marcos conceptuales. Ver al respecto Mascareño, A. Die alt und Jungluhmannianer. En: Farías, I y Ossandón, J. (eds.). Observando sistemas. Nuevas apropiaciones y usos de la teoría de Niklas Luhmann. Santiago, RIL Editores, 2006, p. 377. 
encuentro nunca agotable entre el Evangelio y la historia humana. De ahí que la "transformación de las relaciones sociales, según las exigencias del Reino de Dios, no está establecida de una vez por todas, en sus determinaciones concretas" (Compendio Doctrina Social de la Iglesia No 53 ).

Respecto del carácter inacabado de la DSI, incisivamente Pierre Bigó sostenía: "Una doctrina social auténtica no es un museo de momias maquilladas. Es la memoria viva de la experiencia social de la Iglesia" (2). El encuentro del Evangelio con los problemas que surgen en la vida del hombre en la sociedad no es algo que ya aconteció in toto y de lo cual no queda más que hacer perpetua memoria. Antes bien, tal encuentro está aconteciendo al punto que podríamos decir que la doctrina social de la Iglesia se está originando del encuentro del mensaje evangélico y sus exigencias éticas con los problemas que surgen en la vida de la sociedad. Este rasgo se constituye por sí mismo en una provocación para el diálogo interdisciplinar. Nuevos desarrollos de la teología, nuevos desarrollos de las problemáticas sociales así como nuevas formas de interpretarlas, junto a nuevos desarrollos de las ciencias humanas y sociales, reclaman de un diálogo permanente para el cultivo de una disciplina que se autoentiende como un sistema abierto (3).

Como todo concepto, el de desarrollo tiene su propia historia cuyo develamiento es condición para una cabal comprensión del mismo. Pero no tenemos que ocuparnos de ello aquí. Bástennos con algunas indicaciones para insinuar sus bases normativas. Como anota Larraín, la "idea de desarrollo tal como la conocemos hoy (...) no aparece antes del surgimiento del capitalismo y los comienzos de la modernidad" (4). La emergencia del concepto supuso el paso de un orden socioeconómico fundado en fuerzas productivas que cambiaban muy lentamente y cuyo producto era casi estacionario, a un orden en que las fuerzas productivas dieron origen a un crecimiento económico sin precedentes. El concepto mismo adquiere centralidad en el período de posguerra que ve surgir diversas teorías sobre el desarrollo (5). De alguna manera las concepciones sobre el desarrollo reproducen las visiones ideológicas que se ven enfrentadas en la Guerra Fría. Por un lado, Estados Unidos busca "mostrar la continuidad del proceso de desarrollo capitalista mundial, y que las naciones 'atrasadas' o 'subdesarrolladas' pueden superar los obstáculos al desarrollo dentro del 'mundo libre' para alcanzar los mismos niveles de los países centrales" (6). Por otro lado, el renovado impulso del socialismo vinculado con el poder adquirido por la Unión Soviética en la posguerra "le dio un renovado impulso a la teoría marxista del imperialismo que (...) culpa a los países desarrollados y al colonialismo por el subdesarrollo de la periferia" (7).

Diversas experiencias de desarrollo en el mundo de la posguerra abonaron la incorporación del concepto en la agenda internacional. Se cuentan entre ellos: la

(2) CELAM, Fe cristiana y compromiso social. Santiago, Dpto. de Acción Social del CELAM, 1983, p. 154.

(3) Orientaciones, $\mathrm{N}^{\mathrm{o}} 3$.

(4) Larraín, J. Identidad y desarrollo: una tensión sociológica fundamental en el siglo XX. En: Persona y Sociedad, Vol. XIX (3). Diciembre 2005, p. 48.

(5) Ibíd., p. 49.

(6) Loc. cit.

(7) Loc. cit. 
acelerada reconstrucción posbélica de Alemania y Japón, que emergen como nuevos líderes de la economía mundial; el crecimiento económico sin precedentes de Europa y Norteamérica; la creación del 'Estado de bienestar'; el advenimiento de Asia oriental como región de extraordinario crecimiento económico con un notable desarrollo social y equidad comparativa y el aumento extraordinario del volumen del comercio internacional y el flujo de capitales a escala mundial.

Tales experiencias 'exitosas' generaron un ambiente optimista respecto de las posibilidades de transitar desde el subdesarrollo al desarrollo. Los países que habían logrado levantar el vuelo del crecimiento económico después de las traumáticas experiencias de la guerra pasaron a encarnar el paradigma de país desarrollado.

Entre las teorías del desarrollo en las que es especialmente reconocible el carácter normativo del concepto se cuentan las teorías de la modernización. Para tales teorías el desarrollo se explica "como un proceso necesario de transición por capas entre dos modelos o tipos ideales: la sociedad tradicional y la sociedad moderna o industrial" (8). Ahora bien, esta transición conlleva "el progresivo abandono de valores religiosos y antiguas tradiciones rurales y su reemplazo por los valores de la razón, libertad, progreso y tolerancia" (9). Una transición exitosa al desarrollo exige un ethos cultural con valores específicos para inducirlo: "valores científicos, como el método, la objetividad, el espíritu crítico; valores tecnológicos, como la eficiencia y la utilidad, y los valores éticos, como la libertad y la tolerancia" (10).

Incluso en el presente, una de las variaciones dominantes del concepto consagrado al nivel de Naciones Unidas, como lo es el desarrollo humano, explicita su componente ético y normativo. Surgido con el propósito de "convocar a los agentes del desarrollo en torno a un nuevo paradigma que permitiera enfrentar más eficientemente los retos del desarrollo" (11), se define como la ampliación de "las opciones de que dispone la gente para construir la vida que valora y aumentar sus capacidades para hacer realidad esas opciones" (12). El concepto se sustenta en un deseable humano que entiende "el ejercicio de la libertad como fin último de la existencia humana" (13).

Ahora bien, la incorporación de este concepto en la DSI pasa por un proceso de resignificación. Frente a las teorías del desarrollo existentes a la fecha, que otorgaban una significación aparentemente económica a la categoría de desarrollo, Juan XXIII va a adjetivar la expresión para mejor reflejar de manera inequívoca el aporte original que la Iglesia busca hacer desde su comprensión de lo humano. Para que el desarrollo sea considerado integral es menester evitar la reducción economicista del concepto. "El desarrollo -indicará Pablo VI- no se reduce al simple crecimiento económico" (PP 14), ya sea derivado del orden espontáneo del mercado autorregulado o ya sea derivado del despliegue de un modelo de economía centralmente planificada. Una teoría normativa como la DSI no puede complacerse en la cuantificación

(8) Ibíd., p. 50.

(9) Loc. cit.

(10) Loc. cit.

(11) Güell, P., Los Informes de Desarrollo Humano en Chile: su aporte a la reflexión sociológica. En: Persona y Sociedad, Vol. XIX (3). Diciembre 2005, p. 200.

(12) Loc. cit.

(13) Loc. cit. 
del crecimiento económico como indicador del desarrollo de los pueblos. Para que sea tal debe satisfacer una exigencia antropológica: promover a todos los hombres y a todo el hombre (PP 14). Tanto este epítome como aquel de que el desarrollo es el nuevo nombre de la paz, evocan con fuerza el imperativo moral, individual y colectivo, de trabajar constantemente por el desarrollo de los hombres y pueblos (14). Toda la tematización sobre el desarrollo en la DSI ha supuesto su comprensión como "un proyecto colectivo que exige poseer un modelo de sociedad y consiguientemente una idea determinada del hombre" (15). Es una conexión antropológica la que permite a Juan Pablo II relevar el carácter intrínsecamente moral del desarrollo (SRS 32).

El carácter de teoría normativa de la DSI se comprende mejor si se examina la perspectiva desde la cual la Iglesia habla de lo social. Para la doctrina social de la Iglesia la realidad social queda incomprendida si se reduce a su sola dimensión factual. Las problemáticas sociales no son solo ni fundamentalmente técnicas. Hay una dimensión ético-moral que les es coextensiva y sin la cual no quedan comprendidas en toda su complejidad. En la medida en que se reconoce una proyectividad ética en lo social es que se rechaza la pretensión de la "fuerza normativa de lo fáctico" (16). En este sentido, Juan Pablo II, hablando sobre el desarrollo, sostuvo que este "para que sea auténtico, es decir, conforme a la dignidad del hombre y de los pueblos, no puede ser reducido solamente a un problema "técnico"" (17). Es esta dimensión de la realidad social la que es interpelada por la doctrina social. Como ha sostenido Carrier, la perspectiva específica de la enseñanza social de la Iglesia "es esencialmente la de la teología moral aplicada a los problemas sociales" (18). En sustancia ella no es sino "una aplicación de la teología, sobre todo de la teología moral, a las preguntas éticas que formulan las sociedades humanas" (19). Allí se esclarece la perspectiva desde la cual la Iglesia aborda lo social. La DSI parte de la premisa de que las cuestiones que se abordan "son ante todo morales; y que ni el análisis del problema del desarrollo como tal ni los medios para superar las presentes dificultades pueden prescindir de esta dimensión esencial" (20). Este ángulo de acercamiento a la realidad social deja fuera de su competencia tanto las cuestiones técnicas ("la Iglesia no tiene soluciones técnicas que ofrecer..." (21)), como las científicas ("no corresponde a la Iglesia analizar científicamente la realidad social" (22)). Es así que la Iglesia en su doctrina social busca afrontar las problemáticas

(14) Cozzi, T. Sviluppo. En: Dizionario di Dottrina sociale della Chiesa. Milano, Vita e Pensiero, 2004, pp. 604 ss.

(15) González-Carvajal, L. Entre la utopía y la realidad. Curso de moral social. Santander, Sal Térrae, 1998, p. 179.

(16) Ver el interesante artículo de Fraling, B., En busca de una responsabilidad concretizada. Reflexiones metodológicas de un teólogo moralista acerca de la relación entre las ciencias humanas y la ética teológica, En: P. Hünermann-J. C. Scannone (dirs.), América Latina y la Doctrina Social de la Iglesia, I. Buenos Aires, Paulinas, 1992.

(17) Juan Pablo II, Sollicitudo rei Socialis, N ${ }^{\circ} 41$.

(18) Carrier, H. El nuevo enfoque de la doctrina social de la Iglesia, Ciudad del Vaticano, Pontificio Consejo "Justicia y Paz", s/a, p. 7.

(19) Ibíd, p. 8.

(20) Juan Pablo II, Sollicitudo rei Socialis, $\mathrm{N}^{\circ} 41$

(21) Ibíd., No 41.

(22) Orientaciones, $\mathrm{N}^{\circ} 8$. 
sociales "desde el punto de vista moral y pastoral que le es propio" (23). Con su doctrina social, la Iglesia no pretende "proponer planes técnicos concretos, sino (...) individuar, a la luz de la herencia evangélica, las exigencias éticas y las verdaderas finalidades, dignas del hombre, que deben guiar toda actividad humana, personal y social, privada y pública, económica, política e internacional" (24). Con Juan Pablo II, la DSI llega a autocomprenderse como "la visión moral (25) que intenta asistir a los gobiernos, a las instituciones y las organizaciones privadas para que configuren un nuevo futuro congruente con la dignidad de cada persona. A través de este prisma se pueden valorar las cuestiones que se refieren a la deuda externa de las naciones, a la corrupción política interna y a la discriminación dentro [de la propia nación] y entre las naciones" (26).

Más recientemente, el Compendio de la doctrina social de la Iglesia ha insistido en esta delimitación epistémica de la DSI. Releva la clarificación epistemológica que significó el que en el magisterio de Juan Pablo II se haya establecido su estatuto teológico. "Una clarificación decisiva en este sentido la encontramos, precedida por una significativa indicación en la encíclica "Laborem Exercens", y la encíclica "Sollicitudo rei Socialis": la doctrina social de la Iglesia "no pertenece al ámbito de la ideología, sino al de la teología y especialmente de la teología moral"" (Compendio Doctrina Social de la Iglesia No 72 ).

Convengamos, entonces, que la DSI trata sobre los aspectos éticos de los problemas sociales. De ahí su carácter de teoría normativa. No busca decir cómo suceden las cosas, sino cómo debieran suceder si fueran como debieran ser. Es así que la doctrina social aspira a trazar "los caminos que hay que recorrer para edificar una sociedad reconciliada y armonizada en la justicia y en el amor, que anticipa en la historia, de modo incipiente y prefigurado, los "nuevos cielos y nueva tierra, en los que habite la justicia" (2 P 3, 13)" (Compendio Doctrina Social de la Iglesia No 82).

El desarrollo es abordado desde esta perspectiva, bajo la convicción que lo que la Iglesia tiene para ofrecer se funda en su autocomprensión como experta en humanidad (PP 13). Puesto en términos de Ricoeur, el desarrollo es colocado en el horizonte de un deseable humano que define un criterio contra-fáctico para juzgar de las realizaciones del presente. La Iglesia en su DSI "propone lo que ella posee como propio: una visión global del hombre y de la humanidad" (PP 13).

Un supuesto teórico de la categoría normativa de 'desarrollo integral' es que la modelización de la sociedad no es solo deseable sino también posible. Este supuesto remite a una cuestión a la que la DSI debe prestar mayor atención (allí entiendo se sitúa la crítica de Morandé).

En la primera encíclica dedicada al tema del desarrollo (Populorum Progressio) es reconocible el supuesto del que venimos hablando. Para Pablo VI el desafío es "construir (nótese el verbo) un mundo donde todo hombre sin excepción de raza, religión o nacionalidad, pueda vivir una vida plenamente humana..." (PP 47). El

(23) Ibíd., N $\mathrm{N}^{\mathrm{1}} 13$.

(24) Juan Pablo II, Discurso a los participantes en la solemne conmemoración del XX aniversario de la publicación de la encíclica Populorum Progressio de Pablo VI, 24 de marzo de 1987, $\mathrm{N}^{\circ} 11$.

(25) El subrayado es nuestro.

(26) Juan Pablo II, Ecclesia in America, № 55. 
supuesto de constructibilidad del mundo es también reconocible en el epítome clásico de Populorum Progressio: el desarrollo es el nuevo nombre de la paz; paz que "se construye día a día en la instauración de un orden querido por Dios" (PP 76).

En Sollicitudo rei Socialis (segunda encíclica dedicada al desarrollo) Juan Pablo II postula un parámetro antropológico para la medida y orientación del desarrollo (parámetro interior le llama): un desarrollo pleno, "más humano", procura "estar a la altura de la auténtica vocación del hombre" (SRS 28).

Más recientemente, resulta particularmente visible en el actual Compendio el supuesto de que la sociedad es intencionalmente modelable. Ya desde la Introducción este es reconocible: "La orientación que se imprime a la existencia, a la convivencia social y a la historia, depende, en gran parte, de las respuestas dadas a los interrogantes sobre el lugar del hombre en la naturaleza y la sociedad" (Compendio Doctrina Social de la Iglesia $\left.N^{\circ} 15\right)$. De allí que con este documento se quiera "ofrecer una contribución de verdad a la cuestión del lugar que ocupa el hombre en la naturaleza y en la sociedad" (Compendio Doctrina Social de la Iglesia No 14). La idea normativa de un nuevo orden social, económico y político va y vuelve reiteradamente en el texto: "se busca también proponer a todos los hombres un humanismo a la altura del designio de amor de Dios sobre la historia, un humanismo integral y solidario, que pueda animar un nuevo orden social, económico y político..." (19). La realización de este humanismo integral se considera posible bajo el supuesto de la sociedad concebida como un orden que emerge de las acciones intencionales de los sujetos (epifenomenalismo se denomina a esta concepción teórica en el debate contemporáneo): "Este humanismo podrá ser realizado si cada hombre y mujer y sus comunidades saben cultivar en sí mismos las virtudes morales y sociales y difundirlas en la sociedad..." (Compendio Doctrina Social de la Iglesia No 19). Lo que la DSI busca (y supone) según el Compendio es promover "una sociedad a medida del hombre" (Compendio Doctrina Social de la Iglesia No 63).

La DSI es un discurso normativo sobre la sociedad, pero ¿es moldeable normativamente un mundo crecientemente complejo y diferenciado funcionalmente? La teoría de sistemas sociales desarrollada por Luhmann para describir la evolución de la sociedad compleja y diferenciada ha traído a debate este supuesto que la DSI comparte con toda la tradición viejo europea.

En el contexto de las actuales transformaciones sociales las teorías normativas de la sociedad (como la DSI) enfrentan obstáculos que interrogan radicalmente a su actualidad (cuando no a su disolución). Muchos logran ver el actual 'sentirse perdidos' cultural de las sociedades complejas en Occidente. Muchos también están en condición de observar la pérdida de orientaciones proyectuales (27) en el confluir de la era de la ciencia y la técnica (28) con acelerados procesos de diferenciación

(27) Cf. Donati, P., Pensiero sociale cristiano e società post-moderna. Roma, Editrice a.v e., 1997, p. 16 .

(28) La expresión es de K. O. Apel. 
funcional. La función clásica de la política de ser instancia de orientación normativa de la sociedad se ve, a lo menos, tensionada.

Se ha convertido ya en un tópico el que estamos más que en una época de cambios, en un cambio de época: "No solo se trata de transformaciones dentro de un marco de continuidad. Más que una época de cambios, se vive un verdadero cambio de época" (PNUD, 2000). Ello trae aparejado, entre otras cosas, la crisis de los referentes que cumplían la función de dar seguridad. Crisis que sumada a la complejidad creciente de la sociedad mundial instala la incertidumbre como rasgo distintivo de los tiempos que vivimos. Como observa Giddens, vivimos "en un mundo que nos ha cogido por sorpresa" (29). La incertidumbre en el presente ya no refiere a que la existencia, en el nivel individual o colectivo, sea más arriesgada que la de otras épocas. "Se trata más bien de que las fuentes y el alcance del riesgo han cambiado" (30). Lo que Giddens llama el 'riesgo fabricado', es el resultante "de la intervención humana en la naturaleza y en las condiciones de la vida social" (31).

Pero tal vez el cambio más radical en el presente no sea el llamado "cambio de época', sino el proceso de diferenciación funcional que ha constituido a la sociedad en una sociedad mundial. Lo que vendría a caracterizar a una sociedad mundializada "es su organización sobre la base de la diferenciación interna de funciones a partir de códigos propios y exclusivos de comunicación" (32). La sociedad funcionalmente diferenciada se constituye sobre la base de coordinaciones no intencionales de subsistemas autorreferenciales. Más allá del elenco de susbsistemas ya diferenciados: político (sensible a los votos), jurídico (sensible a la ley positiva), económico (sensible a los precios), educacional (sensible a la acreditación), científico (sensible a la verificación/falsación empírica), medios masivos de comunicación (sensible al rating), salud (sensible a las enfermedades), deportivo (sensible al triunfo), artístico (sensible a la experimentación de las formas), lo que resulta impugnador para las teorías normativas es que "estos subsistemas no aceptan jerarquizaciones objetivas externas a ellos mismos" (33). Solo responden a sus propios códigos. El resultado no intencional de la diferenciación funcional es "una sociedad "acéntrica" o policontextual" (34).

La pérdida de prioridad de un subsistema sobre los otros (por ejemplo, la economía y la política se autonomizan y ya no se puede seguir pensando en dirigir una desde la otra), la autonomización de los subsistemas, la globalización de los procesos sociales, son síntomas de un cambio radical en el modo de configuración de una sociedad mundial (35). La complejidad de la sociedad moderna se deja ver en fenómenos como "la autonomización de los subsistemas, la globalización de los procesos sociales, la pérdida de prioridad de un subsistema por sobre los otros" (36)

(29) Giddens, A., En defensa de la sociología, Madrid, Alianza Editorial, 2000, p. 75.

(30) Loc. cit.

(31) Loc. cit.

(32) Morandé, P. Sociedad contemporánea y persona. En Samuel Yáñez y Diego García (Editores) "El porvenir de los católicos latinoamericanos", Santiago, Centro Teológico Manuel Larraín, 2007, p. 248.

(33) Ibíd

(34) Ibíd.

(35) Rodríguez, D., en Luhmann, N. Organización y decisión. Autopoiesis, acción y entendimiento comunicativo. Santiago, Anthropos, 1997, p. 138.

(36) Ibíd. 
(especialmente relevante para la cuestión que nos ocupa es la pérdida de prioridad de lo político).

La autonomización de los sistemas funcionales autorrefenciales conduce a cuestionar por su raíz una idea secular de sociedad que ha estado a la base de la moderna teoría social y política. Tal idea presupuesta es uno de los obstáculos epistemológicos que Luhmann busca superar con su teoría. Conviene reproducir aquí el conjunto de obstáculos epistémicos que identifica: “1) que la sociedad estaría compuesta de hombres concretos y de las relaciones entre hombres; 2) que, en consecuencia, la sociedad estaría integrada o constituida a través [del] consenso de los hombres, el acuerdo de sus opiniones y la complementariedad de sus objetivos; 3) que las sociedades serían unidades regional y territorialmente limitadas, de modo tal que Brasil es una sociedad distinta a Tailandia, los Estados Unidos una distinta de Rusia, e incluso también Uruguay distinta de Paraguay; 4) y que las sociedades, como grupos de hombres o territorios, podrían ser observadas desde fuera" (37).

La imagen clásica de sociedad forjada en Europa se representaba al hombre en una posición jerárquica privilegiada que le permitía configurar la polis. En esta perspectiva viejo-europea, la sociedad venía siendo representada como una especie de objeto disponible (monocontextual) para ser transformado según los dictámenes de una voluntad política (buena o mala). Mediante la acción política, a partir de su centro rector, los hombres en la sociedad podían alcanzar determinados estados de cosas considerados como deseables (lo que suponía la posibilidad de que a determinadas acciones le siguieran determinadas consecuencias. Tal es la base de la antigua ética europea que posibilitó el "soñar con una sociedad civil ético-política" (38) (sueño del que se nutrió el pensar utópico). La tesis luhmanniana que nos deja perplejos es que esta tradición ética "terminó en el siglo XVII, a más tardar en el XVIII” (39) (¡y nadie - hasta Luhmann- había tenido la delicadeza de avisarnos!). Para Luhmann, la porfía en mantener los sueños sobre la base de que otro mundo es posible, reconocible en los grandes gestos de la política mundial, no es sino expresión de la ignorancia protegida por el desconocimiento de la ignorancia (40).

Desde la teoría de sistemas la sociedad es observada como un orden emergente, esto es, un orden cuya configuración no es resultado de acciones intencionales. "Lo emergente de la sociedad es que su cambio resiste ajustarse a un programa de acción determinado. Cuando la sociedad cambia lo hace en una dirección que nunca coincide exactamente con el plan que los actores habían trazado" (41).

Es así que, a partir de este principio, el sujeto se pierde, haciendo que las sociedades no estén compuestas de hombres concretos y de relaciones entre hombres; la sociedad no es consecuencia del consenso entre los hombres, y no se constituye a través de la coincidencia de sus ideas ni de la complementariedad de sus fines o se integra con ello; las sociedades no son unidades limitadas regional o territorial-

(37) Luhmannn, N. cit. en Mascareño, A. ob. cit., p. 368.

(38) Luhmannn, N., Observaciones de la modernidad. Racionalidad y contingencia en la sociedad moderna, Barcelona, Paidós, 1997, p. 166.

(39) Loc. cit.

(40) Ibíd., p. 170.

(41) Chernilo, D., Mascareño, A. Universalidad, particularismo y sociedad mundial. En: Persona y Sociedad, Vol. XIX (3). Diciembre 2005, p. 40. 
mente, y por tanto, las sociedades como grupos de hombres o como territorios no pueden ser observadas desde fuera. Operar sobre la dualización cartesiana de un sujeto (el experto) observando un objeto (lo social) externo a él mismo, constituye uno de los principales obstáculos epistemológicos que señala Luhmann como supuestos que impiden construir hoy una teoría de la sociedad.

Como anota Antonio González, Niklas Luhmann entiende que si la teoría social se encuentra con dificultades para conceptuar la realidad de la sociedad mundial, ello se debe a que tanto los antiguos como los modernos entendieron la sociedad como un conjunto de hombres unidos por una serie de características comunes. Esto sobre el supuesto de que estas características comunes se articulan políticamente, de manera que la sociedad vendría a ser aquel conjunto humano organizado mediante un determinado Estado nacional. Los límites de una sociedad no serían otros que los límites determinados por las fronteras territoriales de los Estados. Naturalmente, esto se debe a una idea enormemente primitiva de lo social, definido en términos de comunidad y no de diferenciación funcional (42).

La sociedad para Luhmann no está compuesta de seres humanos, sino solo de comunicación. Lo social y los individuos son entidades autónomas. Cada uno actúa con principios de operación diversos (lo social: comunicación; los sistemas psíquicos: conciencia). Luhmann logra aislar lo social de modo que la sociedad aparece como sistema y el individuo como entorno de ese sistema. Desde la teoría de sistemas lo social no puede surgir directamente de la interrelación humana. Para Luhmann, "El hecho de que, a pesar de todas estas evidencias persista el aferrarse a un concepto humanístico de sociedad, es decir, a un concepto que tiene su referencia esencial en el hombre, quizás esté condicionado por el temor a quedarse sin una medida para evaluar la sociedad y, por lo tanto, sin el derecho a pretender que la sociedad se haya de organizar de modo humano" (43).

Para Luhmann, es una comprensión errada de la sociedad la que está a la base de un tal 'prejuicio humanista'. Lo social no está constituido a imagen y semejanza del hombre, sino que es el resultado de una coacción práctica evolutiva; su tendencia es a la reproducción de una dinámica autorreferida. Consiguientemente, lo social nunca ha sido -ni lo es, ni lo será- el espacio de la realización absoluta de las posibilidades más humanas del hombre. La sociedad manifiesta una consistencia propia, una regulación autorreferente que da pie a que cada individuo la experimente en grados de profundidad y en direcciones diversas. Es así que, constituye un verdadero obstáculo epistemológico para pensar la sociedad moderna la "hipótesis de que la sociedad consiste de seres humanos o de relaciones entre ellos. Yo llamo a esto el prejuicio humanista" (44).

Es tal vez el desconcierto que provoca la tesis luhmanniana lo que explica algunos malentendidos de los cuales se hace cargo el mismo Luhmann. Que lo social no esté constituido a imagen y semejanza del hombre no significa que el ser humano no desempeñe ningún papel en la teoría de los sistemas sociales. "Quien llegue a

(42) González, A. Un solo mundo. La relevancia de Zubiri para la teoría social, Tesis doctoral UP Comillas, Madrid, 1995.

(43) Luhmann, N. Teoría de la sociedad, México, Universidad de Guadalajara, 1993, p. 33.

(44) Luhmann, N., Complejidad y modernidad: de la unidad a la diferencia, Madrid, Trotta, 1998, p. 52. 
esta conclusión no ha entendido el planteamiento" (45), sentencia Luhmann. Lo que hace la teoría es situar al hombre en el entorno de la sociedad: "En esta teoría, el hombre no se pierde como entorno del sistema, solo cambia la posición jerárquica de la que gozaba en la antigua teoría europea de la sociedad civil" (46). La irritación moral que ha suscitado esta especie de expulsión del hombre del paraíso de la sociedad, intenta ser explicada como reflejo de la pervivencia de supuestos hoy insustentables. Como lo ha planteado uno de los traductores de la obra de Luhmann a la lengua española: "Si se analiza con precisión la tradición humanista, se descubre que está afincada en presupuestos que actualmente ya no son aceptables" (47). Toda la sociología desde los clásicos, se ha impuesto "la tarea de disponer de una forma de sociedad según la imagen de la esencia del hombre" (48). A las espaldas de esta pretensión de asoma un prejuicio (prejuicio humanista le llama Luhmann), que se constituye en un obstáculo epistemológico "que bloquea el acceso a una descripción suficientemente compleja de la sociedad moderna" (49).

La sociedad, en cuanto relación, se compone siempre menos de personas y personas humanas. Llega a caracterizarse como construcción de formas que no existen en forma natural: la sociedad es cada vez más pensada y actuada como una realidad virtual, hecha de elementos y dinámicas artificiales, cualquier cosa sea lo que la palabra artificial pueda significar. En otras palabras, lo humano se diferencia, y a menudo se disocia de lo social (50).

Como se desprende de lo dicho, la metateoría luhmanniana cuestiona por su base a la ética política y, en ella, al pensar utópico, que opera sobre la pretensión de orientar normativamente (a partir de una idea de 'desarrollo integral', por ejemplo) la sociedad. Si al decir de Luhmann, "La sociedad no es, por suerte, una cuestión de moral" (51), ¿en dónde se sustentan los esfuerzos de la DSI de someter a la sociedad a imperativos ético-morales? ¿Tienen asidero en la sociedad o reflejan más bien su precariedad teórica en la comprensión de la sociedad moderna? Y no se trata de decir aquí que la teoría luhmanniana renuncia a tratar de la moral en perspectiva sociológica. De lo que se trata -si hemos entendido bien- es de distinguir entre el reconocimiento de la moral en la sociedad, de la moralización de la sociedad: "Naturalmente, ninguna sociedad renuncia a la moral, por el simple hecho de que la interacción entre los seres humanos, el problema de la estima recíproca (que es, según Luhmann, donde reside lo moral en la sociedad), se reproduce continuamente" (52).

En suma, distanciándose de otras propuestas teóricas, la teoría de sistemas sociales luhmanniana no ofrece "una utopía, una sociedad modelística ideal a la que se haya de llegar a través de la negación y la superación de las condiciones que

(45) Luhmann, N., Sistemas Sociales, Barcelona, Anthropos, 1998, p. 15.

(46) Loc. cit.

(47) Torres Nafarrate, J., en Luhmann, N., Sistemas Sociales, Barcelona, Anthropos, 1998, p. 24.

(48) Loc. cit.

(49) Loc. cit.

(50) Cf. Donati, P. , op. cit. p. 16

(51) Luhmann, N., Sistemas Sociales, Barcelona, Anthropos, 1998, p. 219.

(52) Ibíd., p. 223. 
caracterizan la sociedad del momento" (53). Desde tal perspectiva teórica, aun la teoría de la acción comunicativa de Habermas es observada como expresión de un deseo bienintencionado (54) (igual cosa se podría afirmar respecto de la DSI). Pero ¿será que una teoría social así concebida no deja ningún espacio para intencionar la orientación normativa de sociedades complejas?

III

¿Qué desafíos surgen desde la crítica luhmanniana al 'prejuicio humanista' que la DSI compartiría con la tradición viejo europea?

Que estas consideraciones teóricas no son indiferentes para la formulación de la DSI es observable en el planteamiento que Morandé nos hacía en la Jornada de enero de 2006. A él le llamaba la atención, repetimos, como científico social, las insuficiencias en la llamada Doctrina Social de la Iglesia, en la que todavía se presenta una visión jerarquizada de la sociedad a partir de lo que Kant llamaba la "voluntad legislativa" de la razón humana. Sobre el mismo problema ha llamado la atención Donati para quien, en la medida en que la modernidad avance, se hace cada vez menos probable tener formas sociales 'naturales' o consideradas como tales. Casi seguramente ya no será posible, como lo ha sido hasta ahora, vivir en una sociedad pensada y actuada como inmediatamente humana, o sea, en la que el elemento humano sea asumido como presupuesto, de alguna forma, dado por hecho (55). De ahí que advierta que el pensamiento social cristiano debe prestar mayor atención al hecho de que la sociedad es otra cosa respecto del hombre, esto es, que existe una creciente distancia entre lo humano y lo social (56). Es decir, la continuidad ya no puede más ser dada por supuesta.

La crítica luhmanniana al 'prejuicio humanista' actualiza para la DSI el imperativo de atender a eventuales teorías sociales implícitas en la formulación de un discurso normativo sobre lo social, como lo es la DSI. A este respecto conviene recordar que ya el teólogo Ratzinger llamaba en la década del 60 la atención sobre el hecho de que en las formulaciones del magisterio social de Iglesia había también componentes ideológicos. Sostenía que al observador de la DSI le acucia la sospecha de que junto a elementos evangélicos y de derecho natural, "se den también elementos ideológicos, es decir, elementos que solo aparentemente pertenecen a la primera o a la segunda categoría, pero que, en verdad, vienen de una estructura social histórica, que es experimentada como 'natural', y por ello, subrepticiamente, dichos elementos corren el riesgo de ser considerados normativos sin serlo" (57).

(53) Rodríguez, D., en Luhmann, N., Organización y decisión. Autopoiesis, acción y entendimiento comunicativo, Barcelona, Anthropos, 1997, p. XV.

(54) Luhmann afirma que la teoría de Habermas "solo puede afirmarse a sí misma como bienintencionada". Ver en ibíd., p. 132.

(55) Donati, P. Pensiero sociale cristiano e società post-moderna, Roma, Editrice a.v e., 1997, p. 16.

(56) Cf. loc. cit.

(57) En Scannone, J.C., Reflexiones epistemológicas acerca de las tres dimensiones (histórica, teórica y práctica) de la doctrina social de la Iglesia. En: P. Hünermann-J. C. Scannone (dirs.), América Latina y la Doctrina Social de la Iglesia, I. Buenos Aires, Paulinas, 1992, pp. 60-61. 
¿Será que, como se puede derivar de la crítica luhmanniana, la DSI absorbió la visión jerarquizada de sociedad (teoría social implícita) propia del mundo viejo europeo?

Por otra parte, considero que la crítica que comentamos también presiona hacia el discernimiento teológico y epistemológico en el recurso a las 'mediaciones socioanalíticas' de cara a los desarrollos de la teoría social contemporánea. Como hemos indicado en otra parte (58), el necesario diálogo con las ciencias sociales no conlleva una recepción acrítica de sus contribuciones. El recurso a las ciencias sociales requiere de una consideración crítica, de un atento discernimiento. De alguna manera -y en ello hay cierta paradoja- la enseñanza social de la Iglesia muestra a ratos una mejor comprensión del estatuto epistemológico de las ciencias sociales. No es aventurado decir que a las mismas ciencias sociales les ha faltado a veces introspección. ¿En qué se funda esta necesidad de discernimiento? No solo en el hecho de que se trata de elaborar un saber teológico, lo que implica que el aporte de las ciencias sociales "debe ser objeto de un discernimiento crítico de naturaleza teológica" (59), sino también, en la conciencia de que las ciencias sociales no son neutras (60). Dado que no todo lo que lleva la etiqueta de científico lo es, "la utilización de un método de aproximación a la realidad debe estar precedido de un examen crítico de naturaleza epistemológica" (61).

Hay que decir entonces $-\mathrm{y}$ nos parece que esa ha sido una constante en la enseñanza social de la Iglesia- que la explicación/comprensión (descripción diría Luhmann) de lo social es irreductible a las ciencias humanas y sociales. Por ello el estudio de lo social requiere de la confluencia dialógica de diversos saberes, entre los cuales no pueden faltar ni la filosofía ni la teología, so pena de reducir a priori, tanto el objeto percibido como el órgano percipiente (según la célebre formula de Horkheimer). Para la DSI, sin la aportación específica de la filosofía y la teología, las ciencias sociales se exponen a "perder de vista el significado profundo y único de su objeto de estudio" (62). El discernimiento de las ciencias sociales, consiguientemente, viene exigido no desde fuera de ellas, desde otros saberes interesados, sino desde dentro del objeto mismo. Es la irreductibilidad de lo social al lenguaje de las ciencias sociales la que impone la exigencia de un examen crítico de sus propios presupuestos.

De los presupuestos que sustentan los análisis sociales la teología ha adquirido una mayor conciencia. No obstante, permanece válida la constatación paradójica que hace Angelini en el sentido que, en el cristianismo actual, junto a un ascenso irresistible de lo social, se constata una penuria llamativa en la reflexión teológico-moral

(58) Parra, F. \& Miranda, P. , Pensamiento social de la Iglesia Católica y ciencias sociales: horizontes teológicos para un diálogo. Santiago, Anales de la Facultad de Teología de la Pontificia Universidad Católica de Chile, 2006 Vol. LVII, 230 pp.

(59) Libertatis Nuntius, 5.

(60) Gutiérrez, G., Teología de la Liberación. Perspectivas. Salamanca, Sígueme, 1994, p. 27.

(61) Congregación para la Doctrina de la Fe, Instrucción sobre algunos aspectos de la 'teología de la liberación'. Santiago, Ediciones Paulinas, 1987, VII, 4.

(62) Oviedo, L., La fe en diálogo: con la razón, la cultura y las ciencias, en César Izquierdo (ed.), Teología fundamental. Temas y propuestas para el nuevo milenio. Bilbao, Desclée de Brouwer, 1999, p. 477. 
con respecto a las realidades sociales (63). Con respecto a los supuestos, y a título de ilustración, la misma teología de la liberación, "que ha usado siempre las ciencias sociales en su campo propio", ha madurado la conciencia de que la ciencia social no es neutra. Como ha sostenido Gutiérrez en la introducción a la decimocuarta edición de su obra clásica Teología de la liberación, Perspectivas, ellas "acarrean un mundo ideológico" (64) que es necesario discernir.

Lo que desde la enseñanza social de la Iglesia se quiere hacer ver es que el lenguaje científico, cualquiera sea el enfoque bajo el cual se cultive, es incapaz de comprender la totalidad del fenómeno social. Y aún más, que el fragmento de realidad social que es objeto de estudio es capturado desde unos determinados a priori metodológicos e ideológicos. La pretensión de neutralidad de las ciencias sociales aparece así como ilusión, ella misma ideológica, en cuanto encubre las precomprensiones que están configurando desde la base sus análisis y proyecciones sobre lo social.

Y no deja de ser sugerente que desde uno de los contendores de la teoría social luhmanniana (Habermas), la crítica de fondo se dirija al eventual carácter conservador de la teoría de sistemas. "Habermas, en su debate con Luhmann en Frankfurt a inicios de los años setenta, calificó la teoría de sistemas como una tecnología social, como la nueva ideología que desliga los criterios legitimatorios de condiciones normativas y los vincula a lo que denomina la acción racional con arreglo a fines del sistema (65)". La teoría de sistemas, según Habermas, vendría a representar "la forma superior de una conciencia tecnocrática" (66) que define de antemano las cuestiones prácticas como cuestiones técnicas. De este modo, el "mundo pasaba de las manos de los hombres a depender de los engranajes de las máquinas descritos en una teoría conservadora de la sociedad" (67).

La crítica habermasiana, siguiendo la huella de los maestros de la sospecha, se pregunta si esta teoría no viene a asumir las funciones legitimadoras de lo establecido, propias de la conciencia positivista (68).

¿Será la crítica del 'prejuicio humanista' la expresión de una sofisticada teoría conservadora de la sociedad? Pero aun si lo fuere queda en pie el problema de la búsqueda de orientación normativa de sociedades complejas. A la luz del debate contemporáneo en teoría social, no parece posible seguir pensando la sociedad como sustentada en un principio rector, al modo de la polis griega. De ahí que la crítica de Morandé a la DSI deba suscitar nuevos desarrollos para mostrar el singular aporte que surge desde la fe cristiana para fecundar y fermentar la sociedad con el Evangelio (Compendio Doctrina Social de la Iglesia № 61).

¿Cómo trabajar por un desarrollo integral en el contexto de sociedades complejas y funcionalmente diferenciadas? Cuando el espectáculo del mundo, desde la

(63) Cit. en Vidal, M., Moral de Actitudes, T. III, Moral Social. Madrid, PS Editorial, 1995, $8^{\text {a }}$ ed., p. 79 .

(64) Gutiérrez, G., ob. cit., p. 27.

(65) Mascareño, A. Ética de la contingencia por medio del derecho reflexivo. En Artur Stamford (ed.), Sociología do Direito. A práctica da teoría sociológica, Lumen Juris, 2006.

(66) Habermas, J. La lógica de las ciencias sociales. Madrid, Tecnos, 2002, p. 311.

(67) Mascareño, A. Ética de la contingencia por medio del derecho reflexivo. En Artur Stamford (ed.), Sociología do Direito. A práctica da teoría sociológica, Lumen Juris, 2006.

(68) Cf. Habermas, J. La lógica de las ciencias sociales, p. 310. 
perspectiva del desarrollo integral, da lamentable actualidad al diagnóstico de Puebla: "tenemos que señalar que después de los años cincuenta y no obstante las realizaciones logradas, han fracasado las amplias esperanzas del desarrollo y han aumentado la marginación de grandes mayorías y la explotación de los pobres" (DP 1260), urge la búsqueda creativa de formas innovadoras de compresión e intervención de una sociedad que ahora se manifiesta como sociedad mundial. No sea que nos ocurra lo que Benedicto XVI afirma que ocurrió con el surgimiento de la cuestión social: "La cuestión del orden justo de la colectividad, desde un punto de vista histórico, ha entrado en una nueva fase con la formación de la sociedad industrial en el siglo XIX. El surgir de la industria moderna ha desbaratado las viejas estructuras sociales y, con la masa de los asalariados, ha provocado un cambio radical en la configuración de la sociedad, en la cual la relación entre el capital y el trabajo se ha convertido en la cuestión decisiva, una cuestión que, en estos términos, era desconocida hasta entonces (...). Se debe admitir que los representantes de la Iglesia percibieron solo lentamente que el problema de la estructura justa de la sociedad se planteaba de un modo nuevo" (69). En una sociedad compleja y diferenciada ¿no habrá también que plantear de un modo nuevo los esfuerzos por un desarrollo integral ante el salto de complejidad de la sociedad mundial? Es alentador que desde la misma tradición sistémica aparezcan búsquedas teóricas fundadas en un impulso ético asociado a la descripción de la sociedad. En esta dirección apuntan los trabajos de Wilke (propuesta de orientación contextual) y de Teubner (política de opciones) (70).

En la década del 70 Pablo VI se refirió a la utopía como esa "forma de crítica de la sociedad establecida [que] provoca con frecuencia la imaginación prospectiva para percibir a la vez en el presente lo posiblemente ignorado que se encuentra inscrito en él y para orientar hacia un futuro mejor" (Octogésima Adveniens, 37) (71). No es difícil imaginar que desde la categoría normativa de 'desarrollo integral' sea posible (y necesario) ensayar una crítica de la sociedad mundial. El problema es cómo modelar una sociedad mundial articulando "las presiones autorregulatorias de los sistemas funcionales, las demandas de autonomía biográfica de los individuos y las demandas de autodeterminación colectiva de la humanidad" (72). Nos parece vital el aporte de la DSI a la recuperación de cierto aliento utópico precisamente para reinstalar "cierta confianza en la capacidad de reorganizar la sociedad" (73) o, para decirlo en términos del PNUD 2002, para "hacer la experiencia de una sociedad capaz de conducir los procesos sociales" (74). Se busca con ello salir al paso de una lógica que termina desplazándose por el plano inclinado de la naturalización de lo

(69) Benedicti XVI, Deus Caritas Est, No 26-27

(70) Ver al respecto A. MASCAREÑO. Die Alt-Und Jungluhmannianer. La autopiesis de la comunicación acerca de la comunicación sistémica. En I. Farías y J. Ossandón (eds.). Observando sistemas, Santiago, 2006.

(71) Pablo VI vincula el renacimiento de las utopías con el esfuerzo por "resolver el problema político de las sociedades modernas" ante la debilidad de las ideologías expresadas en los sistemas concretos en que tratan de realizarse.

(72) Güell, P. ob. cit., p. 212.

(73) Giner, S., Historia del pensamiento social. Barcelona, Ariel Historia, 2002, 10 a ed., p. 190.

(74) Programa de Naciones Unidas para el Desarrollo, Informe sobre el Desarrollo Humano en Chile 2002, PNUD, Santiago, 2002, p. 293. 
social: "Cuando el mecanismo de mercado [u otros mecanismos autorregulados] se cubre con el halo de un orden natural, se debilitan las capacidades individuales y colectivas de moldear el ordenamiento de la vida social" (75). Lo que es tanto como decir que se jubila con honores (76) el sentido del pensar utópico, no solo para balbucear hacia adónde vamos, sino también para sugerir dónde deberíamos ir. Parafraseando a Juan Pablo II podemos decir que no será superfluo examinar de nuevo y en profundidad bajo nuevas luces los temas tratados y las orientaciones características de la DSI en estos años (SRS 42).

\section{RESUMEN}

Pensando en la actualidad de la DSI de cara a los actuales desafíos que se plantean en la sociedad contemporánea, se discute un supuesto fundamental que está a la base del concepto de desarrollo, tal como ha sido trabajado conceptualmente desde Juan XXIII en adelante. En la DSI la categoría de 'desarrollo integral' no solo tiene una explícita connotación normativa, sino que además refleja una teoría social implícita tal que supone una línea de continuidad entre individuo y sociedad. Tal supuesto de continuidad es contestado desde una de las más influyentes teorías sociales contemporáneas, como lo es la de Niklas Luhmann. La teoría de sistemas sociales autorreferenciales se constituye en una verdadera interpelación, cuando no impugnación, a los deseos bienintencionados de toda teoría normativa sobre el desarrollo (entre ellas, la DSI). De ahí que, más que intentar una exégesis del concepto en las formulaciones magisteriales, se indague por su actualidad en el contexto de las transformaciones sociales contemporáneas.

\section{ABSTRACT}

In the present article, pondering the current applicability of the social doctrine of the Church to the challenges of contemporary society, a fundamental supposition grounding the concept of development is discussed, precisely as it has been conceptually worked from John XXIII onwards. In the social doctrine of the Church, the category of "integral development" not only contains an explicit normative connotation, but also reflects an implicit social theory to the extent that it presupposes a line of continuity between the individual and society. Such a supposition of continuity is contested by one of the most influential of contemporary social theories, that of Niklas Luhmann. The theory of self-referring social systems is based on a true interpellation, if not refutation, of the well-intentioned desires of every normative theory of development (among them, the social doctrine of the Church). From this point the author, rather than attempting an exegesis of the concept in the formulations of the Church's magisterium, investigates its present condition in the context of contemporary social transformations.

(75) Ibíd., p. 290.

(76) En alusión a la jubilación con honores que Luhmann refiere respecto de Kant, Durkheim, Parsons, etc. 